\title{
A Current Meter Using a Phototube (II)
}

- Experiment on a Wind Drift Current in a Rising State -

\author{
by \\ T. Nan'niti \\ Meteorological Research Institute \\ (Received August 14, 1953)
}

\begin{abstract}
The author observed a drift current in a rising state using his newly designed current meter [1], and he could distinguish in a recorded chart a rising drift current, a proper ocean current and an apparent ocean current caused by a swing of the current meter due to the yawing, pitching and rolling of the research ship "Asasiwo Maru" in bad sea conditions.
\end{abstract}

\section{Materials}

The experiment was performed in Sagami Bay on board the research ship “Asasiwo Maru" on May 15, 1953, using three current meters of different kinds simultaneously, such as an Ekman-Merz, an Ono's (Hydrographic Office) and the

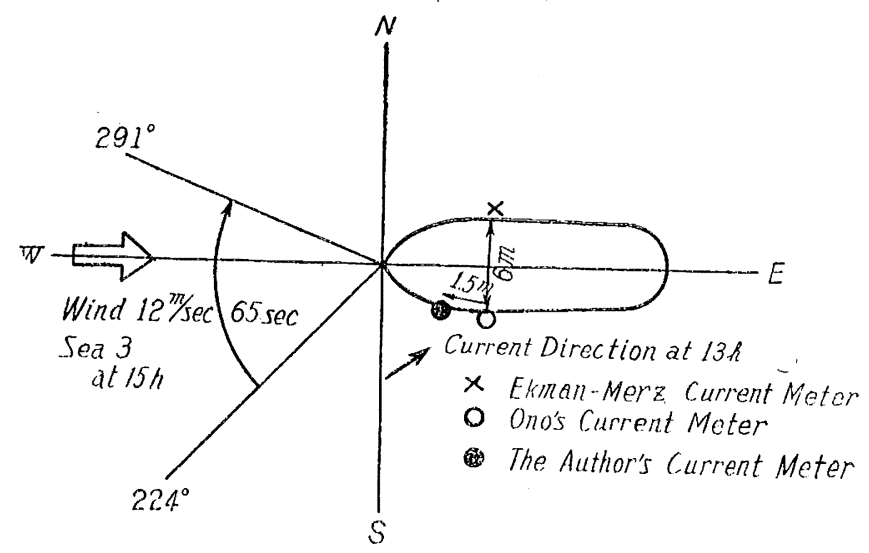

Fig. 1. Positions of the three current meters in the simultaneous observation. The arrows show the directions of wind, sea and current as observed by vision. author's current meters. Their relative positions in the experiment are shown in Fig. 1.

Just before the ship reached a station the wind had risen to a gale at about $10 \mathrm{~h} 40 \mathrm{~m} \sim 50 \mathrm{~m}$, and then the sea surface. began to be covered with white horses. The ship reached the station $\left(34^{\circ}\right.$ $\left.59^{\prime} .5 \mathrm{~N}, 139^{\circ} 05^{\prime} .7 \mathrm{E}\right)$ at $11 \mathrm{~h}$ $10 \mathrm{~m}$.

The observation was done at a layer of $5 \mathrm{~m}$ depth. The direction of current, as seen from the deck, was NE or NNE and turned to the east gradually, perhaps by the westerly wind. Oceanographical data obtained by the Ekman-Merz current 
meter, meteorological data and others are tabulated in Table 1.

Table 1. Oceanographical observation taken in Sagami Bay.

Station $34^{\circ} 59^{\prime} .5 \mathrm{~N}, 139^{\circ} 05^{\prime} .7 \mathrm{E}$. Date May 15, 1953. Mag. Var. $5^{\circ} \mathrm{W}$.

Tide (at Ito) H.W. $4 \mathrm{~h} 45 \mathrm{~m}, 18 \mathrm{~h} 55 \mathrm{~m}$; L.W. $12 \mathrm{~h} 10 \mathrm{~m}$. Lunar Age 1.9 day

(1) Direct current measurement taken by an Ekman-Merz current meter Depth $5 \mathrm{~m}$

\begin{tabular}{|c|c|c|c|c|}
\hline Time & Speed & Dir. & Distribution of balls & \\
\hline $\begin{array}{rr}\mathrm{h} & \mathrm{m} \\
13 & 23\end{array}$ & $\begin{array}{c}\mathrm{cm} / \mathrm{sec} \\
19.3\end{array}$ & 218 & $12 / 1,14 / 1,20 / 2,21 / 1,34 / 1,35 / 1$ & . \\
\hline 1340 & 15.8 & 55 & $1 / 1,14 / 1,17 / 1,18 / 1,33 / 2,34 / 1$ & \\
\hline 1359 & 14.6 & 60 & $0 / 1, \quad 1 / 2,9 / 1,11 / 1,17 / 1$ & \\
\hline $1450 ?$ & ? & 40 & $0 / 2, \quad 1 / 1, \quad 2 / 1, \quad 5 / 1,7 / 2,8 / 2$, & $13 / 1,34 / i$ \\
\hline
\end{tabular}

(2) Marine-meteorological observation

\begin{tabular}{|c|c|c|c|c|c|}
\hline Time & Air temp. & Wind & Clouds & Sea & Swell \\
\hline $\begin{array}{ll}\mathrm{h} & \mathrm{m} \\
8 & 00\end{array}$ & ${ }^{\circ} \mathrm{C}$ & $\begin{array}{lc}\text { dir. } & \text { speed } \\
\text { SW } & 2 \text { (in Beaufort's) }\end{array}$ & clear sky & & \\
\hline 1200 & & W 5 (in Beaufort's) & clear sky & & \\
\hline 1500 & 21.5 & $W \quad 12.0 \mathrm{~m} / \mathrm{sec}$ & $1 \mathrm{C} \dot{\mathrm{i}}, \mathrm{OAC}$ & W 3 & none \\
\hline 16. 00 & & W 6 (in Beaufort's) & clear sky & & \\
\hline
\end{tabular}

(3) Movement of the ship

Time taken for yawing from $224^{\circ}$ to $291^{\circ} \ldots \ldots \ldots \ldots 65 \mathrm{sec}$.

Period of rolling....................... 5 sec.

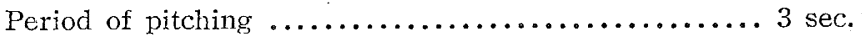

From a bad record obtained by the Ono's current meter, it is very difficult to read any speed or direction of the current, due to bad sea conditions. Balls of the Ekman-Merz current meter are also distributed in various directions due to bad sea conditions, so the average direction is uncertain.

Next, a part of the chart recorded by the author's cnrrent meter at a 5 m layer is shown in Fig. 2. As mentioned in the previous paper [1], the speed calibration

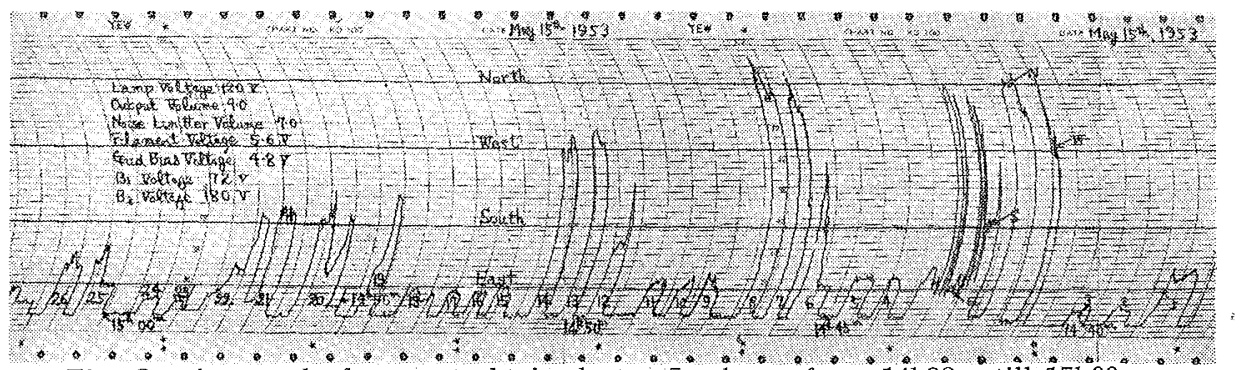

Fig. 2. A record of current obtained at a $5 \mathrm{~m}$ layer from $14 \mathrm{~h} 38 \mathrm{~m}$ till $15 \mathrm{~h} 00 \mathrm{~m}$.

was not done. So a comparison about current speed obtained by simultaneous 
observations with the Ekman-Merz and the author's current meters was done, and the result is shown in Fig. 3. From the figure we may add $1.8 \mathrm{~cm} / \mathrm{sec}$ to the calculated speeds by the author's current meter. We must also add this value to the results obtained in the previous paper [1]. Adding this correction to the values calculated from Fig. 2, we get the results tabulated in Table 2 and shown in Figs. 4 and 5. In this table and the figures, the records obtained when the light path was opened were numbered in time order. After this, at about $15 \mathrm{~h} 03 \mathrm{~m}$,

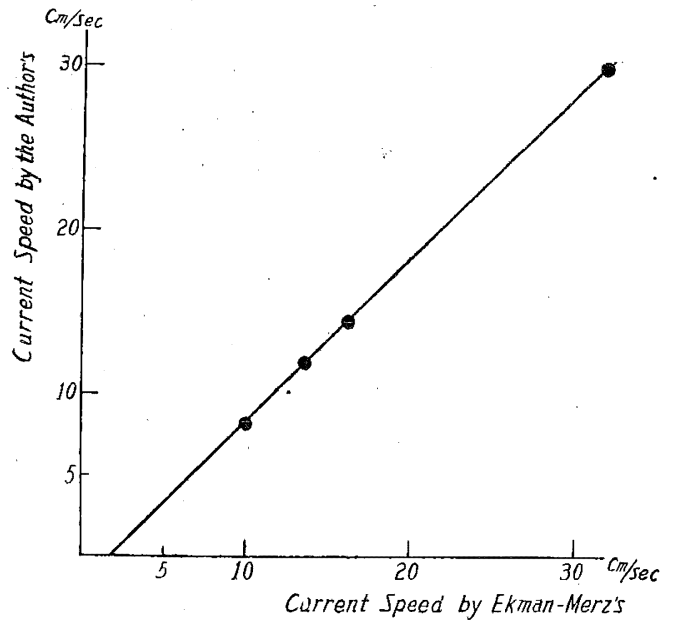

Fig. 3. Relation between the speeds obtained by a Ekman-Merz and by the author's current meters.

the sea surface became more and more rough, so we stopped the observation.

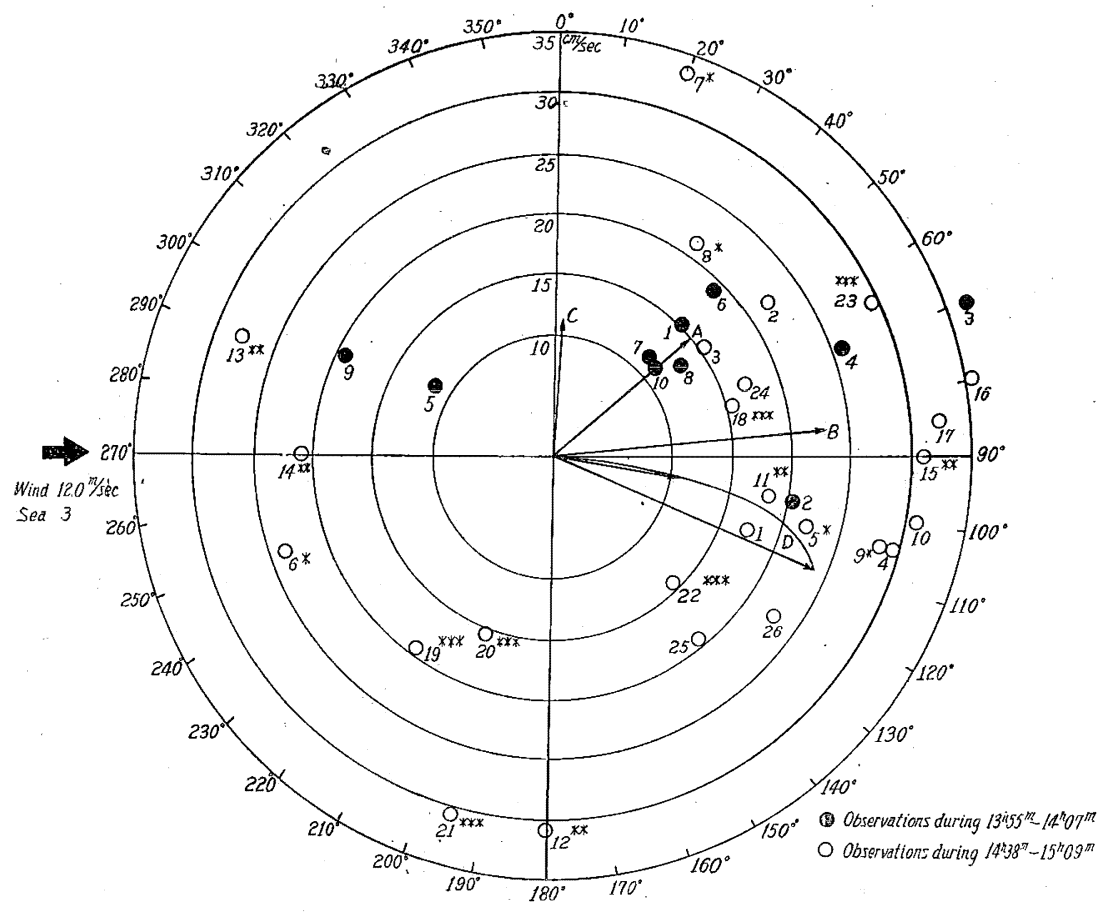

Fig. 4. Vectors of velocities of the recorded current at every instance and the mean currents at $14 \mathrm{~h}(\mathrm{~A})$ and at $15 \mathrm{~h}(\mathrm{~B})$; and the proper (C) and the wind currents deduced from them. A hodograph of rising wind current (D) is also shown. 
Table 2. Direct current measurement taken by the author's current meter at a $5 \mathrm{~m}$ layer from $14 \mathrm{~h} 38 \mathrm{~m}$ till $15 \mathrm{~h} 00 \mathrm{~m}$.

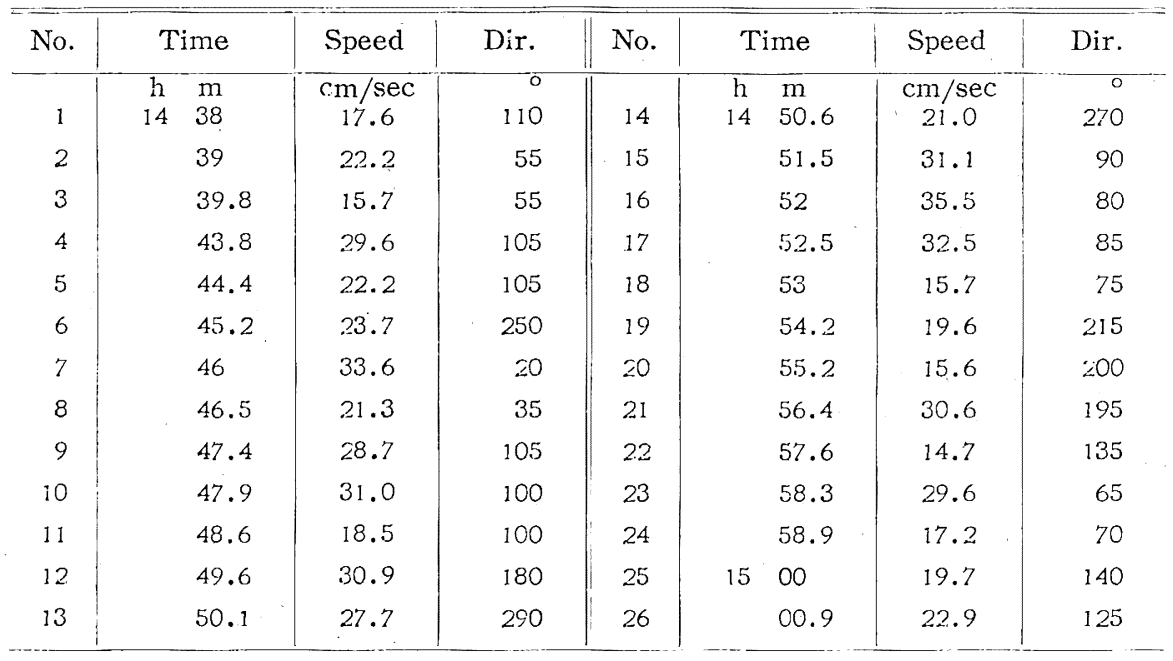

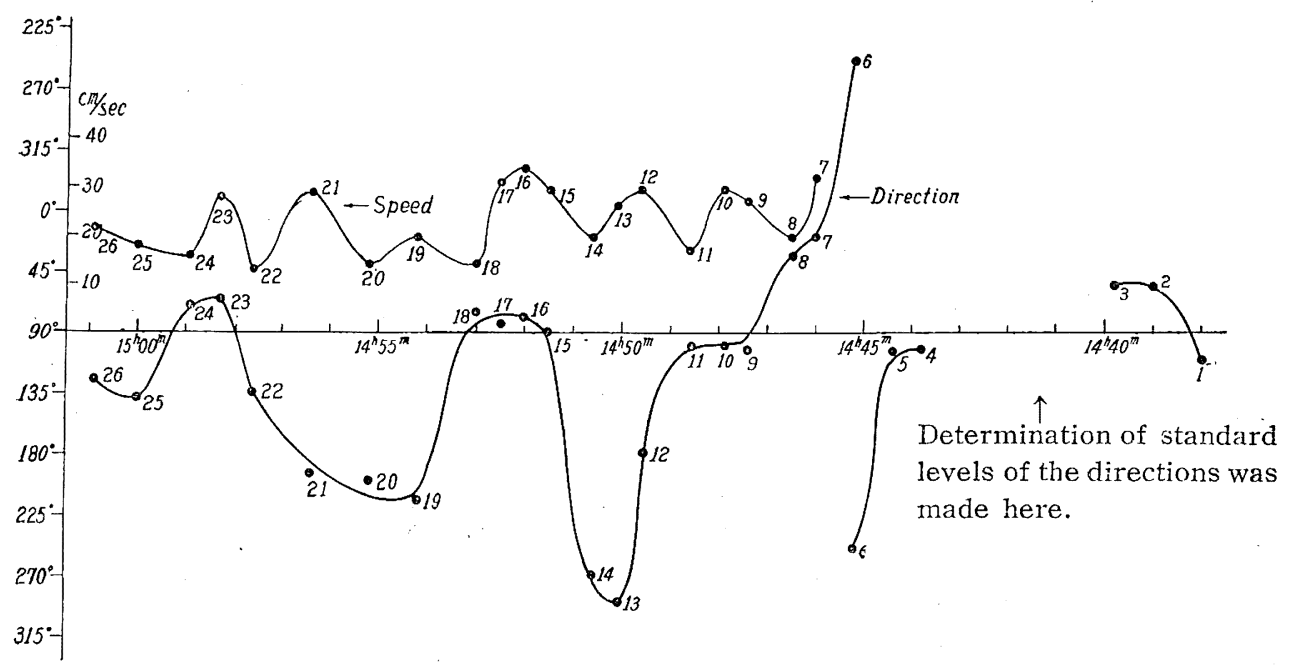

Fig. 5. Oscillation of the current meter caused by the ship's yawing due to the gale.

\section{Analysis of materials}

From Figs. 4 and 5, we can find that the current meter changed its direction remarkably about four times in 15 minutes. We have marked the records of each cycle by affixing to the numbers the signs*,**,*** in Fig. 4. It might not occur that the real ocean current changed its speed rapidly and its direction widely in such a manner. And the observation was carried out in bad sea conditions, so we 
can suspect that the instrument was swung with a period of two or three minutes around its main direction, the east. And as the current ran towards NE, the ship oscillated anti-symmetrically with reference to the $\mathrm{E}-\mathrm{W}$ direction, i.e. it oscillated larger towards NE. (See Fig. 1). For, we can see that recorded speeds decreased in their values on that chart at points $2-3,4-5,7-8,10-11,13-14,16-17-18,19-20$, $21-22,23-24$; and increased in their values at the points $1-2,5-6-7,8-9-10,11-12-13$, 14-15-16, 18-19, 20-21, 22-23, 24-25-26. We can explain these facts by supposing that the ocean current itself did not change just as was recorded, but that the instrument was swung by the ship's movement, namely speeds in increasing state: were recorded when the instrument was swung strongly, being suspended from a meter wheel as the ship was yawing by the strong wind, and speeds in decreasing state were recorded as the instrument was nearly free from oscillation, or it was near the turning points of its pendulum motion.

At $15 \mathrm{~h} 00 \mathrm{~m}$ the ship itself was yawing from $224^{\circ}$ to $291^{\circ}$ taking $65 \mathrm{sec}$ as shown in Table 1 , so it took about 2 min $10 \mathrm{sec}$ in order for the spip to swing one cycle. The record in Fig. 2 shows that the instrument was swung in two or three minutes. and then rested about equal minutes and again swung as before. And recorded. currents in Fig. 4 pointed mostly towards the direction between $44^{\circ}\left(=224^{\circ}-180^{\circ}\right)$ and $111^{\circ}\left(=291^{\circ}-180^{\circ}\right)$. As shown in Figs. 2 and 5 , the swing of the current meter was damped and its direction gradually tended to the east for more than 15 minutes. The damping oscillation shown in Fig. 5 would not be caused by a real variable current speed and direction as the meter wheel, the suporting point of the current meter, did not swing, because its amplitude was too large. But it could be caused by the swing of the supporting point due to the ship's yawing. In this observation, the ship dropped only one anchor, so the above-mentioned yawing occured, which we could put an end to by dropping one more anchor.

Furthermore, we can see the fluctuation in the direction of the order of $20^{\circ} \sim$ $40^{\circ}, 5 \mathrm{sec}$ in Fig. 2. These periods of the fluctuation coincided with the periods of rolling or pitching of the ship.

By a complex combination of an apparent current induced by the ship's rolling, pitching and yawing and the ocean current, the recorded chart mentioned above was obtained; and in these disturbances, the apparent current, the effect of yawing was the largest.

We get the mean value, $23 \mathrm{~cm} / \mathrm{sec} 85^{\circ}$, as the ocean current omitting the apparent current and averaging the values obtained at such points as $2-3,4-5,10-11$, 16-17 and 23-24, where recorded directions were kept constant for about one or two minutes. At these points, it seems that the instrument was nearly at rest, being: free from the ship's swinging around (see Figs. 4, and 5). 
Next we investigate the current condition before $14 \mathrm{~h} 38 \mathrm{~m}$. We tabulate the results in Table 3 calculated from Fig. 6 obtained at a $5 \mathrm{~m}$ layer from $13 \mathrm{~h} 55 \mathrm{~m}$ till $14 \mathrm{~h} 07 \mathrm{~m}$. Plorting these values in Fig. 4, we get the mean value, $15 \mathrm{~cm} / \mathrm{sec}$ $50^{\circ}$, as the ocean current.

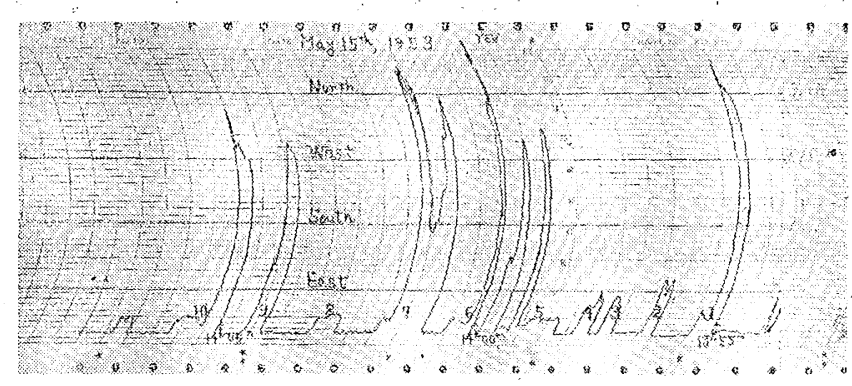

Fig. 6. Another record of current obtained at the $5 \mathrm{~m}$. layer from $13 \mathrm{~h} 55 \mathrm{~m}$ till $14 \mathrm{~h} 07 \mathrm{~m}$.

Table 3. Direct current measurement taken by the author's current meter at a $5 \mathrm{~m}$ layer from $13 \mathrm{~h} 55 \mathrm{~m}$ till $14 \mathrm{~h} 05 \mathrm{~m}$.

\begin{tabular}{|c|c|c|c|c|c|c|c|c|c|}
\hline No. & \multicolumn{2}{|c|}{ Time } & Speed & Dir. & No. & \multicolumn{2}{|c|}{ Time } & Speed & Dir. \\
\hline & & $\mathrm{m}$ & $\mathrm{cm} / \mathrm{sec}$ & 0 & & & $\mathrm{~m}$ & $\mathrm{~cm} / \mathrm{sec}$ & O \\
\hline 1 & & 55 & 15.3 & 45 & 6 & 14 & 00 & 19.3 & 45 \\
\hline 2 & & 56.3 & 20.6 & 100 & 7 & & 01.8 & 11.5 & 45 \\
\hline 3 & & 57.1 & 36.9 & 70 & 8 & & 03 & 13.2 & 55 \\
\hline 4 & & 57.8 & 25.8 & 70 & 9 & & 04.4 & 19.3 & 295 \\
\hline 5 & & 59 & 11.4 & 300 & 10 & & 05.5 & $\cdot 11.3$ & 50 \\
\hline
\end{tabular}

\section{Discussion of the above section}

As shown in Table 1, the distribution patterns of balls of the Ekman-Merz current meter were very irregular. Assuming that 7 balls were dropped in 5 minutes, the current meter kept a constant direction, less than 10 degrees, only for $43 \mathrm{sec}$ or $86 \mathrm{sec}$, because we found only one or two balls in each compartment of the compass box, and the angular velocity of yawing was (291-224)/65=1.03 $\mathrm{deg} / \mathrm{sec}$. If we assume that the current meter was swung with an angular velocity $1.0 \mathrm{deg} / \mathrm{sec}$, the current meter changed its direction by $30^{\circ}$ in $30 \mathrm{sec}$. And when it came to the turning point, or it was nearly free from osciliation, it was at rest for $120 \mathrm{sec}$, so it dropped one or two balis in one compartment. It is not quite probable that two balls were dropped in one and the same compartment in the going and coming of the swing. So it would be natural that the balls were spread in such a wide extent as they were observed to be. Time for one cycle of yawing was four to five minutes and the time interval taking for one current observation by the Ekman-Merz's was also five minutes. So the values observed by the Ekman-Merz's were not so widely different from the average values obtained by the author's. But if the period of yawing was larger, the time interval for one observation by the Ekman-Merz's had to be taken also larger.

The wind began to blow hard from the west at $10 \mathrm{~h} 40 \mathrm{~m} \sim 50 \mathrm{~m}$. At $14 \mathrm{~h} 00 \mathrm{~m}, 3$ hours after the rising of the gale, the speed of the ocean current was $15 \mathrm{~cm} / \mathrm{sec}$, 
its direction was $50^{\circ}$; and at $15 \mathrm{~h} 00 \mathrm{~m}, 4$ hours after the rising of the gale, the current speed was $23 \mathrm{~cm} / \mathrm{sec}$, its direction was $85^{\circ}$ (see Fig. 4).

4 hours after the rising of the gale, the speed of wind current would have been almost developed. And it is well known that the average value of wind factor is 0.02 . So let the speed of wind current be $1200 \times 0.02=24 \mathrm{~cm} / \mathrm{sec}$ and its direction be $105^{\circ}$ or $110^{\circ}$ or $115^{\circ}$ as $h / D=1 / 4,(D=150 \mathrm{~m})[2]$. Though the depth of the station, $15 \mathrm{~m}$, was estimated from a sea chart, its position was near the coast and the depth of its offing was $30 \mathrm{~m} \sim 60 \mathrm{~m}$. So we take $h / D=1 / 4$ as the representative value of this sea. We have the proper ocean current in Table 4.

Table 4. The proper ocean current calculated when the wind current is assumed.

\begin{tabular}{|c|c|c|c|c|c|c|}
\hline \multirow{2}{*}{$\begin{array}{l}\text { Assumed wind current } \\
\text { (speed } 24 \mathrm{~cm} / \mathrm{sec} \text { ) }\end{array}$} & \multicolumn{6}{|c|}{ Direction } \\
\hline & \multicolumn{2}{|c|}{$105^{\circ} \cdot$} & \multicolumn{2}{|c|}{$110^{\circ}$} & \multicolumn{2}{|c|}{$115^{\circ}$} \\
\hline Proper ocean current & $\begin{array}{l}\text { speed } \\
\mathrm{cm} / \mathrm{sec} \\
8.6\end{array}$ & $\begin{array}{r}\text { dir. } \\
359\end{array}$ & $\begin{array}{l}\text { speed } \\
\mathrm{cm} / \mathrm{sec} \\
10.5\end{array}$ & $\underset{0}{\operatorname{dir} .}$ & $\begin{array}{c}\text { speed } \\
\mathrm{cm} / \mathrm{sec} \\
12.4\end{array}$ & $\begin{array}{c}\operatorname{dir} . \\
5\end{array}$ \\
\hline
\end{tabular}

At $14 \mathrm{~h}$, the resultant ocean current was $15 \mathrm{~cm} / \mathrm{sec}, 50^{\circ}$, and if the proper ocean current at $14 \mathrm{~h}$ was also $10.5 \mathrm{~cm} / \mathrm{sec}, 3^{\circ}$, the wind current at $14 \mathrm{~h}$ was $11.2 \mathrm{~cm} / \mathrm{sec}$, $94^{\circ}$; and if the proper current was $12.4 \mathrm{~cm} / \mathrm{sec}, 5^{\circ}$, the wind current was $10.8 \mathrm{~cm} / \mathrm{sec}$ $104^{\circ}$. So the wind current increased its speed by $24-11.2=12.8 \mathrm{~cm} / \mathrm{sec}$ and turned its direction by $110-94=16^{\circ}$ to the right for an hour, or increased its speed by $24-10.8=13.2 \mathrm{~cm} / \mathrm{sec}$, and turned its angle by $115-104=11^{\circ}$ to the right.

But the culculated wind current at $14 \mathrm{~h}$ was smaller than the theoretical one. Perhaps the disagreement was caused by the assumption that the proper current was stationary. The directions in this paper are all mentioned referring to the geomagnetic axes. The magnetic variation at the station is $5^{\circ} \mathrm{W}$.

The periods of rolling and pitching were $5 \mathrm{sec}$ and $3 \mathrm{sec}$ respectively (see Table 1 ). Though we did not observe the period of the sea, we calculated it [3 and got $3 \mathrm{sec}$. As the period of the sea has an intermediate value between the periods of rolling and pitching, the yawing will be damped [4], though the bow of the ship was fastened by the chain, and it was restricted in its movement in some degree and received the force of the ocean current from the port. Thus the yawing had been damped as shown in Fig. 5 .

There were no recording instruments for meteorological elements, and the data of the ocean current in initial condition were not obtained, so we can not discuss them further.

\section{Conclusion}

The author observed a current on a strong windy day, and he could observe 
it successfully. The proper ocean current was $11.5 \mathrm{~cm} / \mathrm{sec}, 4^{\circ} .3$ hours after the rising of the gale, $12 \mathrm{~m} / \mathrm{sec}, 90^{\circ}$, the wind current was $11.0 \mathrm{~cm} / \mathrm{sec}, 99^{\circ}$, and 4 hours after the beginning it was $24 \mathrm{~cm} / \mathrm{sec}, 113^{\circ}$, it increased its speed by $13 \mathrm{~cm} / \mathrm{sec}$, and turned its direction by $14^{\circ}$ to the right for an hour.

Acknowledgement-The author wishes to express his hearty thanks to Dr. M. Nakano for his kind advice, and to the members of the Oceanographical Section, of the Central Meteorological Observatory for their help during the observation.

\section{References}

[1] Nan'nimi, T., 1953: A Current Meter Using a Phototube (I). Papers in Meteorology and Geophysics, 3, p. 286.

[2] Нирлка, K., 1933: Non-Stationary Ocean-Current, Part 1. Memoirs of the Kobe Marine Observatory, 5, p. 141.

[3] Sverdrup, H.U. and W.H. Munk, 1947: Wind, Sea and Swell; Theory of Relations for Forecasting. Contribution from the Scripps Institution of Oceanography. New Series No. 303.

[4] SEZawa, K., 1935: The Theory of Oscillations (in Japanese). Tokyo, Iwanami-Shoten. p. 467. 